\title{
Calculation of Diffusion Coefficients in Ternary Systems from Diaphragm Cell Experiments*
}

\author{
P. R. Patel, ${ }^{* *}$ E. C. Moreno, ${ }^{* *}$ and T. M. Gregory** \\ Institute for Materials Research, National Bureau of Standards, Washington, D.C. 20234 \\ (September 17, 1968)

\begin{abstract}
Using a generalized least square procedure, a method is developed to estimate diffusion coefficients, $D_{i j}$, from concentration measurements made in a set of experiments of varying duration but with the same initial conditions. The method requires neither approximations nor restrictions in the flow equations. The $D_{i j}$ and their errors are calculated simultaneously with the adjustment of the weighted observables-concentrations of the two solute components and time. A procedure is described to insure convergence in a given experimental set. The effect of the duration of the longest experiment, and errors in the observables on the estimated values of $D_{i j}$ and their errors, are investigated. Application of the method to available data yielded values for $D_{i j}$ in agreement with those previously calculated by more involved procedures.
\end{abstract}

Key Words: Diaphragm cell; diffusion coefficients; least squares calculation; ternary system.

\section{Introduction}

The methods reported for the calculation of diffusion coefficients in ternary systems from diaphragm cell data require either restrictions in the experimental conditions $[1,2]^{1}$ or approximations in the flux equations [3]. A new method is reported here that obviates the limitations of previous procedures when concentrations of the diffusing solutes are directly measured in the cell compartments. Although the present method was derived independently of a procedure recently reported by Cussler and Dunlop [4], the two approaches to the problem are similar. The present derivations, however, allow a more complete and direct treatment of the subject, particularly for the calculation of errors.

\section{Theory}

The general equations that define diffusion flows, $\left(J_{i}\right)_{V}$, in ternary systems relative to a volume-fixed frame of reference are $[5,6]$.

*This investigation was supported in part by Research Grants DE-01819 and DE-02659 to the American Dental Association from the National Institute of Dental Research, and is part of the dental research program conducted by the National Bureau of Standards in cooperation with the Council on Dental Research of the American Dental Association; the National Institute of Dental Research; the Army Dental Corps; the Dental Sciences Division, School of Aerospace Medicine, USAF; and the Veterans Administration.

${ }^{* *}$ Research Associates from the American Dental Association in the Dental Fesearch Section, National Bureau of Standards, Washington, D.C. 20234.

${ }^{1}$ Figures in brackets indicate the literature references at the end of this paper.

$$
\left(J_{i}\right)_{V}=-\sum_{j=1}^{2}\left(D_{i j}\right)_{V} \frac{\partial C_{j}}{\partial x} \quad(i=1,2)
$$

in which $\left(D_{i j}\right)_{V}$ are practical diffusion coefficients and $C_{j}$ is the concentration of component $j$. Integration of eq (1), considering the conditions for the diaphragm cell, assuming linear concentration gradients and no changes in volume during the diffusion process, gives the general solution [7]

$$
\Delta \mathrm{C}_{i}=A_{i} e^{-\beta m_{1} t}+B_{i} e^{-\beta m_{2} t} \quad(i=1,2)
$$

in which $\Delta C_{i}$ is the concentration difference (molar scale is used throughout these derivations) of component $i$ between the two compartments at any time $t$, $\beta$ is the cell constant and the other quantities are defined by

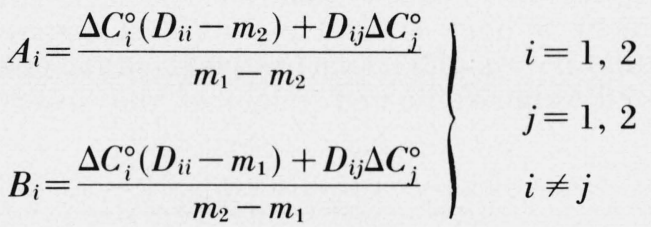

$$
\begin{aligned}
& m_{1}=\frac{1}{2}\left[D_{11}+D_{22}+\sqrt{\left(D_{11}+D_{22}\right)^{2}-4\left(D_{11} D_{22}-D_{12} D_{21}\right)}\right] \\
& m_{2}=\frac{1}{2}\left[D_{11}+D_{22}-\sqrt{\left(D_{11}+D_{22}\right)^{2}-4\left(D_{11} D_{22}-D_{12} D_{21}\right)}\right]
\end{aligned}
$$


In eqs (3) and (4), $\Delta C^{\circ}$ denotes concentration differences at $t=0$, and $D_{i j}$ are the integral cell diffusion coefficients. ${ }^{2}$

The calculation of $D_{i j}$ is accomplished by a generalized least squares procedure [8] using eq (2) as the mathematical model. Thus, the condition equations are of the form

$$
\begin{aligned}
& F=\left(X_{1}-X_{2}\right)-A_{1} e^{-\beta m_{1} T}-B_{1} e^{-\beta m_{2} T} \\
& L=\left(Y_{1}-Y_{2}\right)-A_{2} e^{-\beta m_{1} T}-B_{2} e^{-\beta m_{2} T}
\end{aligned}
$$

in which $X$ and $Y$ represent the concentrations of components 1 and 2 , respectively, in the compartments indicated by their subscripts at the observation time $T .^{3}$

If observations (determinations of $X$ and $Y$ ) are made at the end of $N$ diffusion experiments (with the same initial conditions) of duration $T_{1}, T_{2}, \ldots$, $T_{N}$, then there will be $2 N$ condition equations. The observations corresponding to different values of $T$ are statistically independent, since for each duration, a new experiment is conducted. The number of condition equations may not be a multiple of 2 , however, if either $X$ or $Y$ is not determined at the end of some of the experiments.

When observations are made in only one of the compartments, for example compartment 2 , the condition equations take the form

$$
\begin{aligned}
& F^{\prime}=\left(\Delta X^{\circ}+2 X_{2}^{\circ}-2 X_{2}\right)-A_{1} e^{-\beta m_{1} T}-B_{1} e^{-\beta m_{2} T} \\
& L^{\prime}=\left(\Delta Y^{\circ}+2 Y_{2}^{\circ}-2 Y_{2}\right)-A_{2} e^{-\beta m_{1} T}-B_{2} e^{-\beta m_{2} T}
\end{aligned}
$$

in which $\Delta X^{\circ}$ and $\Delta Y^{\circ}$ are concentration differences for the two components at time $T=0$.

The aim of the procedure is to compute the adjustments of the observables and the corrections for the initial estimates of the diffusion coefficients in such a way that

$$
\begin{gathered}
F^{(n)}\left(x_{1}^{(n)}, x_{2}^{(n)}, t^{(n)}, \Delta x^{\circ}, \Delta y^{\circ}, D_{11}, D_{12}, D_{21}, D_{22}\right) \approx 0 \\
(n=1,2, \ldots, N)
\end{gathered}
$$

and

$L^{(n)}\left(y_{1}^{(n)}, y_{2}^{(n)}, t^{(n)}, \Delta x^{\circ}, \Delta y^{\circ}, D_{11}, D_{12}, D_{21}, D_{22}\right) \approx 0$

in which $x, y, t, \Delta x^{\circ}$, and $\Delta y^{\circ}$ are adjusted observables, and $D_{i j}$ are the final estimates of coefficients. This adjustment is done subject to the least squares criterion that the weighted sum of squares of the residuals (observed value-adjusted value) of the observables

2 Usually, diffusion experiments in a diaphragm cell will yield values for integral diffusion coefficients. However, if $\Delta C_{i}^{\circ}$ is selected sufficiently small, the calculated $D_{i j}$ will approach the values for differential diffusion coefficients. The present treatment will apply equally well for such conditions. The functional relationships between the integral $D_{i j}$ and concentration of the components in ternary systems are not known. Attempts have been made to solve this problem for some particular systems $[\mathrm{P}$. F. Mijnlieff and H. A. Vreedenberg, J. Phys. Chem. 70, 2158 (1966)] but a general analytical solution involves formidable J. Phys. Chem. 70, 2158 mathematical difficulties.
mather

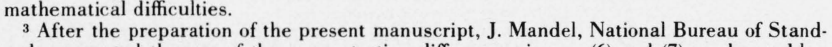
ards suggested the use of the concentration differences in eqs (6) and (7) as observables, instead of working with individual concentration terms. The present procedure would apply equally well for this case.
$X, Y, T, \Delta X^{\circ}$, and $\Delta Y^{\circ}$ be a minimum. In these derivations, the cell constant, $\beta$, is considered as an "external parameter," that is, a quantity obtained from independent experiments, and therefore, not susceptible of adjustment. However, the error in $\beta$ is taken into account in the estimation of the error bounds for $D_{i j}$, as explained below.

Linearization of the condition equations (6) and (7) is done about the observed points $\left(X_{1}, X_{2}, T, \Delta X^{\circ}, \Delta Y^{\circ}\right.$, $\left.D_{11}^{\circ}, D_{12}^{\circ}, D_{21}^{\circ}, D_{22}^{\circ}\right)$ and $\left(Y_{1}, Y_{2}, T, \Delta X^{\circ}, \Delta Y^{\circ}, D_{11}^{\circ}, D_{12}^{\circ}\right.$, $D_{21}^{\circ}, D_{22}^{\circ}$ ) using the best available initial estimates, $D_{i j}^{\circ}$, for the diffusion coefficients. A procedure to obtain good initial estimates for $D_{i j}$ is described later.

The $2 N$ reduced condition equations, resulting from the linearization mentioned above, may be written, in matrix notation,

$$
B V+P \alpha=M
$$

in which $B$ is the matrix $(2 N \times[5 N+2])$ of the derivatives of the condition functions [6] and [7] with respect to the observables, $V$ is the column vector $([5 N+2] \times 1)$ of the residuals, $P$ is the matrix $(2 N \times 4)$ of the derivatives of the condition functions with respect to $D_{i j}, \alpha$ is the column vector $(4 \times 1)$ of the corrections for the $D_{i j}^{\circ}$ (i.e., $\alpha_{i j}=D_{i j}^{\circ}-D_{i j}$ ) and $M$ is the column vector $(2 N \times 1)$ of the values of the condition functions. The condition functions and their derivatives are evaluated using the experimental values of the observables and the initial estimates for the diffusion coefficients.

The sum of squares of the residuals, $S^{2}$, is given by

$$
S^{2}=\tilde{V} W V
$$

in which $W$ is the diagonal matrix of the weights, $W_{\text {obs }}$, for the $5 N+2$ observables and the tilde represents transposition. These weights are calculated from

$$
W_{\mathrm{obs}}=\frac{\sigma_{\mathrm{int}}^{2}}{\sigma_{\mathrm{obs}}^{2}}
$$

in which $\sigma_{\text {obs }}$ is the standard deviation for the observable in question and $\sigma_{\text {int }}$ is an arbitrary constant conveniently selected for calculation purposes.

Minimization of $S^{2}$ (eq (13)) subject to the conditions (12), effected by the use of a Lagrange multiplier, $\Lambda$, and the subsequent elimination of $V$, results in $2 N+4$ normal equations with $2 N$ unknown $\lambda$ 's (the elements of column vector $(\Lambda)$, and four unknown $\alpha_{i j}$. As shown by Guest [9] this leads to the following equations:

$$
\left[\begin{array}{ll}
R & P \\
\tilde{P} & 0
\end{array}\right] \times\left[\begin{array}{l}
\Lambda \\
\alpha
\end{array}\right]=\left[\begin{array}{c}
M \\
0
\end{array}\right]
$$

or

$$
G \times\left[\begin{array}{c}
\Lambda \\
\alpha
\end{array}\right]=\left[\begin{array}{c}
M \\
0
\end{array}\right]
$$

in which $R=B W^{-1} \tilde{B}$, of dimension $2 N \times 2 N$. 
The solution of the above system of equations yields

$$
\left[\begin{array}{l}
\Lambda \\
\alpha
\end{array}\right]=G^{-1}\left[\begin{array}{c}
M \\
0
\end{array}\right]
$$

Since $G^{-1}$ is symmetric, like $G$, it can be partitioned similarly as follows:

$$
G^{-1}=\left[\begin{array}{cc}
Q & H \\
\tilde{H} & C
\end{array}\right]
$$

Then, the solutions for $\Lambda$ and $\alpha$ can be written as,

$$
\begin{aligned}
& \Lambda=Q M \\
& \alpha=\tilde{H} M
\end{aligned}
$$

The values thus obtained for $\alpha_{i j}$ can be now used to calculate new estimates for $D_{i j}$, since

$$
D_{i j}=D_{i j}^{\circ}-\alpha_{i j}
$$

These new estimates of $D_{i j}$ are used iteratively as initial estimates (substituting for $D_{i j}^{\circ}$ ) until convergence in $S^{2}$, calculated by eq (13), is obtained. At this point the final residuals are calculated from $V=W^{-1} \tilde{B} \Lambda$. The error vector $\Delta,\left(\Delta D_{11}, \Delta D_{12}, \Delta D_{21}, \Delta D_{22}\right)$, can be found from the $4 \times 4$ error submatrix, $E=-C$, of $G^{-1}$ :

$$
\Delta=\sigma_{\mathrm{ext}} \sqrt{E_{j j}}
$$

in which the standard error, $\sigma_{\text {ext }}$, is given by $\sqrt{\left\{S^{2} /(2 N-4)\right\}}, 2 N-4$ being the degrees of freedom. A discrepancy between the ratio $\sigma_{\text {ext }}^{2} / \sigma_{\text {int }}^{2}$ and unity is an indication of disagreement between the variances assumed in the calculations (based on previous experience) and the error variances actually existing in the experiment $[10]$.

The errors as obtained from eq (19) do not reflect the influence of the error, $\sigma_{\beta}$, in the independently determined cell constant $\beta$. Therefore, calculations are repeated using successively the values $\beta+\sigma_{\beta}$ and $\beta-\sigma_{\beta}$ for the cell constant. A $t$-test is then performed between the $D_{i j}$ obtained in this fashion and those obtained when $\beta$ was considered free of error. If the $t$-test indicates no significant difference, at a selected level of significance, the errors obtained for the $D_{i j}$ with the assumption that $\sigma_{\beta}=0$ may be adopted. Otherwise, a confidence band for the $D_{i j}$ should be estimated.

A requirement for the convergence of the iterative procedure in the calculation of $D_{i j}$ is that the initial estimates of these parameters be close to the final estimates. Various procedures have been suggested $[11,12,13]$ to insure convergence in problems of this nature. In this investigation it was found that, for ternary systems, good initial estimates for only two of the four coefficients are required to insure convergence, their identity being determined by the initial experimental conditions. Three cases of initial conditions are possible in a ternary system: (1) Both dif- fusing components have nonzero concentration gradients; (2) Component 1 has a nonzero gradient and component 2 has a zero gradient; (3) Component 2 has a nonzero gradient and component 1 has a zero gradient. The two diffusion coefficients for which good initial estimates are required in each one of the three cases are: for case (1) $D_{11}$ and $D_{22}$; for case (2) $D_{11}$ and $D_{21}$; and for case (3) $D_{22}$ and $D_{12}$. The initial estimates for the remaining 2 coefficients in each case can be taken as zero. In the flux equations (1) the main contribution to the flux of one component is given by those terms involving the component for which there is an initial concentration gradient. Then, ignoring, as a first approximation, those terms that contribute the least to the diffusion fluxes, performing the corresponding integrations, the resulting expressions may be written in the logarithmic form,

$$
\ln \frac{\Delta C_{i}}{\Delta C_{j}^{\circ}}=-D_{i j} \beta t \quad \begin{aligned}
& i=1,2 \\
& j=1,2
\end{aligned}
$$

which covers the three cases given above. The required initial estimates of the diffusion coefficients are then obtained by a simple linear regression using the appropriate experimental data. In this way, convergence was obtained after 4 to 6 cycles in all the cases tested.

\section{Test of the Method}

The procedure was thoroughly tested by constructing artificial "experimental" data. The condition functions (8) and (9) were used assuming a value of zero for $X_{2}^{\circ}$ and $Y_{2}^{\circ}$. Exact solutions of eqs (2) were obtained for different arbitrary sets of $D_{i j}, \beta$, and initial concentration differences. The "true" points thus obtained were transformed into "experimental" observations by the use of a table of normal deviates, and the foregoing method was applied to these data. ${ }^{4}$ Thus the following factors affecting the estimated values for $D_{i j}$ and their errors were investigated: (a) duration of the longest experiment in a given set of experiments, (b) number of experiments (total number of observations) in sets having the same duration for the longest experiment, and (c) errors in the observables.

For the case of binary systems, expressions have been reported $[14,15]$ to calculate an optimum experimental time at which the fractional error in the diffusion coefficient becomes minimum. Derivation of similar expressions for ternary systems involves such complexity that it is practically unmanageable. In the present investigation this subject was studied by calculations of $D_{i j}$ for different sets of experiments, varying the duration of the longest experiment in each set. A sample of the results obtained is shown

\footnotetext{
4 All the values given in the tables in this paper were calculated assuming that the rela tive precision in the determination of the observables (except time) remained constant This situation is often found when concentrations are directly determined by chemical analyses; the volume of the aliquots is selected so as to analyze essentially the same amoun of component in the samples. The adjustment procedure, however, is general and satis. factory results are also obtained by considering absolute precision.
} 
in table 1. The time given at the top of each column corresponds to the longest experiment in a set consisting of eight experiments, the time increment for each successive experiment being one-eighth of the longest experiment. Values for the percent decrease of the initial concentration differences of components 1 and $2, R_{1}$ and $R_{2}$, at the end of the longest experiment for a particular set are given in the second and third rows. In order to facilitate the interpretation of these calculations, the same random numbers were used to estimate the "experimental" observations for each set. For this reason, the ratio $\sigma_{\text {ext }}^{2} / \sigma_{\text {int }}^{2}$ is fairly constant in this table and, as might have been anticipated, its value is close to unity.

Table 1 shows that as the duration of the longest experiment increases, the estimated $D_{i j}$ approach the values for the "true" diffusion coefficients. Furthermore, the last row in the table shows that there is a minimum in the sum of squares of the errors in $D_{i j}$, $\Sigma \Delta_{i j}^{2}$, corresponding to a set with an experiment of maximum duration between 200 and $600 \mathrm{hr}$. This type of calculation was also performed with a number of systems varying the initial conditions and the (true) values for $D_{i j}$. In all cases a minimum was found but its position varied from system to system and there was no apparent trend correlating the minimum with the parameters used or calculated. In some of the systems studied, the approach to and departure from the minimum value of $\Sigma \Delta_{i j}^{2}$ occurred very gradually as the duration of the longest experiment increased. In other systems, however, the valley region was very narrow. Typical examples of these features are shown in figure 1 in which the quantity $\Sigma \Delta_{i j}^{2}$ is plotted against the duration of the longest experiment in various experimental sets. Initial conditions and related param-

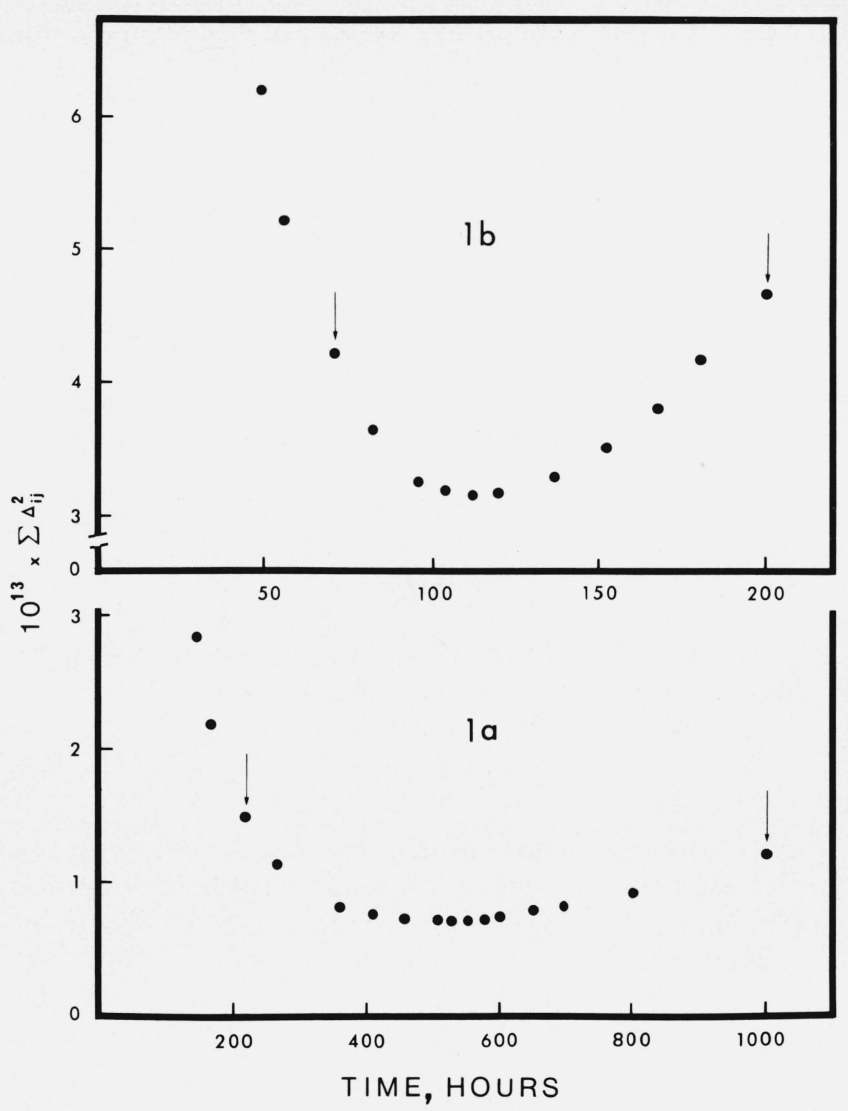

FigURE 1. Effect of duration of longest experiment on errors in $\mathrm{D}_{\mathrm{ij}}$. For both plots: Number of experiments per set, initial conditions, errors in observables, and cell constant, as given in table 1 . For la, "true" $D_{i j}$ as in table 1 . For $1 \mathrm{~b}$, "true" $D_{i j} \times 10^{5}: D_{11}=8.0, D_{12}=1.0, D_{21}=-2.0, D_{22}=4.0$.

TABLE 1. Effect of duration of the longest experiment on the estimated values and errors of the diffusion coefficients

\begin{tabular}{|c|c|c|c|c|c|c|c|c|c|}
\hline $\begin{array}{c}\text { Duration of } \\
\text { longest exp., } h r^{*}\end{array}$ & 24 & 120 & 216 & 312 & 408 & 504 & 600 & 800 & $\begin{array}{l}\text { True diff. } \\
\text { coeffs. }\end{array}$ \\
\hline $\begin{array}{l}R_{1}=100 \Delta X / \Delta X^{\circ} \\
R_{2}=100 \Delta Y / \Delta Y^{\circ}\end{array}$ & $\begin{array}{l}83.2 \\
90.5\end{array}$ & $\begin{array}{l}39.5 \\
61.2\end{array}$ & $\begin{array}{l}18.3 \\
42.0\end{array}$ & $\begin{array}{r}8.1 \\
29.1\end{array}$ & $\begin{array}{r}3.4 \\
20.4\end{array}$ & $\begin{array}{r}1.2 \\
14.3\end{array}$ & $\begin{array}{r}0.2 \\
10.1\end{array}$ & $\begin{array}{r}-0.3 \\
4.9\end{array}$ & \\
\hline$D_{11} \times 10^{5}$ & $\begin{array}{r}1.576 \\
\pm 0.155\end{array}$ & $\begin{array}{r}1.935 \\
\pm 0.033\end{array}$ & $\begin{array}{r}1.959 \\
+0.021\end{array}$ & $\begin{array}{r}1.967 \\
\pm 0.018\end{array}$ & $\begin{array}{r}1.971 \\
\pm 0.016\end{array}$ & $\begin{array}{r}1.973 \\
\pm 0.016\end{array}$ & $\begin{array}{r}1.974 \\
\pm 0.017\end{array}$ & $\begin{array}{r}1.975 \\
\pm 0.019\end{array}$ & 2.000 \\
\hline$D_{12} \times 10^{5}$ & $\begin{array}{r}0.888 \\
\pm 0.252\end{array}$ & $\begin{array}{r}0.296 \\
\pm 0.049\end{array}$ & $\begin{array}{r}0.255 \\
\pm 0.030\end{array}$ & $\begin{array}{r}0.240 \\
\pm 0.023\end{array}$ & $\begin{array}{r}0.233 \\
\pm 0.021\end{array}$ & $\begin{array}{r}0.229 \\
\pm 0.020\end{array}$ & $\begin{array}{r}0.226 \\
\pm 0.020\end{array}$ & $\begin{array}{r}0.221 \\
\pm 0.022\end{array}$ & 0.200 \\
\hline$D_{21} \times 10^{5}$ & $\begin{array}{r}0.062 \\
\pm 0.052\end{array}$ & $\begin{array}{r}0.103 \\
\pm 0.011\end{array}$ & $\begin{array}{r}0.103 \\
\pm 0.008\end{array}$ & $\begin{array}{r}0.103 \\
\pm 0.006\end{array}$ & $\begin{array}{r}0.103 \\
\pm 0.006\end{array}$ & $\begin{array}{r}0.103 \\
\pm 0.006\end{array}$ & $\begin{array}{r}0.103 \\
\pm 0.006\end{array}$ & $\begin{array}{r}0.103 \\
\pm 0.006\end{array}$ & 0.100 \\
\hline$D_{22} \times 10^{5}$ & $\begin{array}{r}1.062 \\
+0.085\end{array}$ & $\begin{array}{r}0.997 \\
+0.017\end{array}$ & $\begin{array}{r}0.997 \\
\pm 0.011\end{array}$ & $\begin{array}{r}0.998 \\
+0.008\end{array}$ & $\begin{array}{r}0.998 \\
+0.007\end{array}$ & $\begin{array}{r}0.998 \\
+0.007\end{array}$ & $\begin{array}{r}0.998 \\
+0.007\end{array}$ & $\begin{array}{r}0.999 \\
+0.007\end{array}$ & 1.000 \\
\hline$\frac{\sigma_{\text {ext }}^{2}}{\sigma_{\text {int }}^{2}}$ & 0.72 & 1.07 & 1.08 & 1.08 & 1.08 & 1.07 & 1.08 & 1.09 & \\
\hline$\left(\Sigma \Delta_{i j}^{2}\right) \times 10^{13}$ & 97.614 & 3.909 & 1.489 & 0.946 & 0.770 & 0.724 & 0.744 & 0.916 & \\
\hline
\end{tabular}

Initial conditions: $\Delta X^{\circ}=0.025 ; \Delta Y^{\circ}=0.015$. Cell constant: $\beta=0.1$.

Total number of experiments in a set: 8 .

Adopted errors: $E_{X, Y}= \pm 0.2 \% ; E_{T}= \pm 60 \mathrm{~s} ; E_{\Delta X^{\circ}, \Delta Y^{\circ}}= \pm 0.1 \% ; E_{\beta}=0.1 \%$.

* Same set of random numbers used for each column. 
TABLE 2. Effect of number of experiments in a set on the estimated values and errors of the diffusion coefficients*

\begin{tabular}{|c|c|c|c|c|c|c|c|}
\hline $\begin{array}{l}\text { Number of } \\
\text { experiments }\end{array}$ & \multicolumn{2}{|c|}{3} & \multicolumn{2}{|c|}{5} & \multicolumn{2}{|c|}{8} & $\begin{array}{l}\text { True diff. } \\
\text { coeffs. }\end{array}$ \\
\hline$D_{11} \times 10^{5}$ & $\begin{array}{r}2.005 \\
\pm 0.027\end{array}$ & $\begin{array}{r}1.938 \\
\pm 0.026\end{array}$ & $\begin{array}{r}2.051 \\
\pm 0.015\end{array}$ & $\begin{array}{r}2.010 \\
\pm 0.022\end{array}$ & $\begin{array}{r}2.002 \\
\pm 0.010\end{array}$ & $\begin{array}{r}1.973 \\
\pm 0.016\end{array}$ & 2.000 \\
\hline$D_{12} \times 10^{5}$ & $\begin{array}{r}0.197 \\
\pm 0.029\end{array}$ & $\begin{array}{r}0.261 \\
\pm 0.028\end{array}$ & $\begin{array}{r}0.151 \\
\pm 0.018\end{array}$ & $\begin{array}{r}0.202 \\
\pm 0.025\end{array}$ & $\begin{array}{r}0.189 \\
\pm 0.012\end{array}$ & $\begin{array}{r}0.228 \\
\pm 0.020\end{array}$ & 0.200 \\
\hline$D_{21} \times 10^{5}$ & $\begin{array}{r}0.114 \\
\pm 0.009\end{array}$ & $\begin{array}{r}0.088 \\
\pm 0.009\end{array}$ & $\begin{array}{r}0.097 \\
\pm 0.005\end{array}$ & $\begin{array}{r}0.096 \\
\pm 0.008\end{array}$ & $\begin{array}{r}0.103 \\
\pm 0.003\end{array}$ & $\begin{array}{r}0.103 \\
\pm 0.006\end{array}$ & 0.100 \\
\hline$D_{22} \times 10^{5}$ & $\begin{array}{r}0.986 \\
\pm 0.010\end{array}$ & $\begin{array}{r}1.012 \\
\pm 0.010\end{array}$ & $\begin{array}{r}1.003 \\
\pm 0.006\end{array}$ & $\begin{array}{r}1.004 \\
\pm 0.009\end{array}$ & $\begin{array}{r}0.994 \\
\pm 0.004\end{array}$ & $\begin{array}{r}0.998 \\
\pm 0.007\end{array}$ & 1.000 \\
\hline$\frac{\sigma_{\text {ext }}^{2}}{\sigma_{\text {int }}^{2}}$ & 0.58 & 0.58 & 0.47 & 0.99 & 0.40 & 1.08 & \\
\hline
\end{tabular}

Initial conditions: $\Delta X^{\circ}=0.025 ; \Delta Y^{\circ}=0.015$. Cell constant; $\beta=0.1$.

Longest experiment in each set: $516 \mathrm{hr}$.

Adopted errors: $E_{X, Y}= \pm 0.2 \% ; E_{T}= \pm 60 \mathrm{~s} ; E_{\Delta X 0 . \Delta Y 0}= \pm 0.1 \% ; E_{\beta}= \pm 0.1 \%$.

*Entries in subcolumns are extreme values of $D_{i j}$ obtained with 6 to 10 sets of randomized data.

eters are given in the figure caption. The lower curve corresponds to the example given in table 1; however, both plots are restricted to the regions adjacent to the minimum. Values for $D_{i j}$ estimated from the experimental sets represented by the points between arrows in figure 1 do not differ appreciably.

The actual position of the minimum in $\Sigma \Delta_{i j}^{2}$ for a given system shifts for different values of the cell constant, $\beta$, but it always occurs at approximately the same values of $R_{1}$ and $R_{2}$. In the absence of analytical expressions to calculate optimum diffusion times in ternary systems, the procedure reported here can be used to determine the duration for which a minimum in the errors for $D_{i j}$ is obtained. This approach, of course, requires estimates for the values of $D_{i j}$, errors in the observables, initial conditions, and the cell constant. With these parameters, curves like those in figure 1 can be computed and a decision about the diffusion time can be made.

The effect of the number of experiments in a set on the estimated values of $D_{i j}$ is shown in table 2 . Calculations for this table were made using the same initial conditions and set of parameters used in table 1. The longest time used in any particular set was $516 \mathrm{hr}$, and the time increment for the $N$ singular experiments was $516 / N$. The calculations were carried out several times for each set using different sets of random numbers for the estimation of the "experimental" observations. Results for the two sets of calculations displaying the maximum differences in $D_{i j}$ are given in the table. It is apparent that as the number of experiments in each set is increased, the variations in $D_{i j}$ and $\Delta_{i j}$ due to experimental errors decrease although the duration of the longest experiment in all the sets was the same, $516 \mathrm{hr}$.

The errors in the observables not only affect the estimated values for $D_{i j}$ and $\Delta_{i j}$, but also the time at which a minimum in $\Sigma \Delta_{i j}^{2}$ is obtained for a given system. Such effects are shown in table 3; the values for $D_{i j}$ were calculated from sets having an experiment with a maximum duration equal to the time for which a minimum in $\Sigma \Delta_{i j}^{2}$ was observed. With large errors in the observables, the values for $D_{i j}$ obtained by the adjustment procedure may be very inaccurate; this situation is particularly true for the cross-term diffusion coefficients. Although definite shifts in the location of the minima in $\Sigma \Delta_{i j}^{2}$ are apparent, they are hardly significant for experimental planning.

TABLE 3. Effect of errors in observables on the estimated values and errors of the diffusion coefficients

\begin{tabular}{|c|c|c|c|c|}
\hline$E_{X, Y}$ & $2.0 \% *$ & $0.2 \% *$ & $0.02 \% *$ & $\begin{array}{l}\text { True diff. } \\
\text { coeffs. }\end{array}$ \\
\hline$D_{11} \times 10^{5}$ & $\begin{array}{r}1.742 \\
\pm 0.147\end{array}$ & $\begin{array}{r}1.973 \\
\pm 0.016\end{array}$ & $\begin{array}{r}1.997 \\
\pm 0.002\end{array}$ & 2.000 \\
\hline$D_{12} \times 10^{5}$ & $\begin{array}{r}0.465 \\
\pm 0.181\end{array}$ & $\begin{array}{r}0.228 \\
\pm 0.020\end{array}$ & $\begin{array}{r}0.203 \\
\pm 0.002\end{array}$ & 0.200 \\
\hline$D_{21} \times 10^{5}$ & $\begin{array}{r}0.130 \\
\pm 0.055\end{array}$ & $\begin{array}{r}0.103 \\
\pm 0.006\end{array}$ & $\begin{array}{r}0.100 \\
\pm 0.001\end{array}$ & 0.100 \\
\hline$D_{22} \times 10^{5}$ & $\begin{array}{r}0.978 \\
+0.068\end{array}$ & $\begin{array}{r}0.998 \\
\pm 0.007\end{array}$ & $\begin{array}{r}1.000 \\
\pm 0.001\end{array}$ & 1.000 \\
\hline$\left(\Sigma \Delta_{i j}^{2}\right) \times 10^{13}$ & 62.025 & 0.723 & 0.008 & \\
\hline $\begin{array}{l}\text { Duration of } \\
\text { longest experi- } \\
\text { ment, hr }\end{array}$ & 532 & 516 & 536 & \\
\hline
\end{tabular}

Initial conditions: $\Delta X^{\circ}=0.025 ; \Delta Y^{\circ}=0.015$. Cell constant: $\beta=0.1$. Total number of experiments in a set: 8 .

Adopted errors: $E_{\Delta X^{\circ}, \Delta Y^{\circ}}= \pm 0.1 \% ; E_{\beta}= \pm 0.1 \% ; E_{T}= \pm 60 \mathrm{~s}$.

*Same set of random numbers used for each column. 
The adjustment procedure described in this paper was applied to the diffusion data reported by Kelly [1] for the ternary system mannitol (1) $-\mathrm{NaCl}(2)-\mathrm{H}_{2} \mathrm{O}$, using the condition eqs (6) and (7). Kelly had obtained the values for $D_{i j}$ from the results of two experimental arrangements with initial conditions given at the head of table 4 . His results and the results obtained by the present procedure are shown, side by side, in the same table.

There is satisfactory agreement between the results obtained by the present procedure and those obtained by Kelly for systems where he could calculate diffusion coefficients, with the exception of the value for $D_{11}$ in the system $2-A$. The values for $D_{i j}$ estimated from Kelly's experimental data for system 1-A should have agreed, in theory, with those obtained from the experimental data for the system $1-B$. The cause of these discrepancies is that, usually, when one of the components has zero initial concentration gradient, the amount diffused is so small that a reliable estimation of the $D_{i j}$ is impossible.

The discrepancies in systems $2-A$ and $2-B$ are explained on the same basis; however, the large value for the ratio $\sigma_{\text {ext }}^{2} / \sigma_{\text {int }}^{2}$ for system 2-A suggests that the error variances used for the observables are very different from those actually existing in this system; for this reason, the values for $D_{i j}$ obtained from this experiment are questionable.

Cussler and Dunlop [4] also estimated $D_{i j}$ from Kelly's data. It is not clear in their publication whether they combined the data for systems $1-\mathrm{A}$ and $1-\mathrm{B}$ or estimated $D_{i j}$ from each arrangement separately. The values they obtained are in good agreement with those obtained by the present method and reported in table 4 , with the exception of the value for $D_{21}$ which is about 5 percent lower than the figure reported here. Significant differences, however, do exist between the errors reported by Cussler and Dunlop and those obtained in the present investigation. This is not surprising because in their unweighted least squares procedure, those investigators arrived at estimates of errors for the $D_{i j}$ by a bound method. Their reported error figures correspond to the maximum difference between the $D_{i j}$ calculated considering the nominal value of the observables and the $D_{i j}$ obtained through similar calculation but using the values of the observables as the nominal values minus their errors and plus their errors, respectively. The procedure given in this paper to calculate $\Delta_{i j}$ is not only time saving but also it has a sound statistical basis.

The authors are indebted to L. J. Gosting, Institute for Enzyme Research, Wisconsin University, Madison, Wisconsin, for making available to them the material of reference (1) and to R. P. Wendt, Department of Chemistry, Loyola University, New Orleans, Louisiana, for his suggestions and critical review of the manuscript.

TABLE 4. Comparison of Kelly's estimated values of the diffusion coefficients with those estimated by the present procedure using Kelly's experimental data for the system mannitol $(\mathrm{X})-\mathrm{NaCl}(\mathrm{Y})-\mathrm{H}_{2} \mathrm{O}$

\begin{tabular}{|c|c|c|c|c|c|c|c|c|}
\hline $\begin{array}{c}\text { Average } \\
\text { conc. }\end{array}$ & \multicolumn{4}{|c|}{$\bar{X}=0.2 M ; \bar{Y}=1.5 M$} & \multicolumn{4}{|c|}{$\bar{X}=0.2 M ; \bar{Y}=3.0 M$} \\
\hline $\begin{array}{l}\text { Initial } \\
\text { conditions }\end{array}$ & \multirow{2}{*}{\multicolumn{2}{|c|}{$\begin{array}{c}\Delta X^{\circ}=0.4 \\
\Delta Y^{\circ}=0.0 \\
1-\mathrm{A} \\
5 \text { experiments }\end{array}$}} & \multirow{2}{*}{\multicolumn{2}{|c|}{$\begin{array}{c}\Delta X^{\circ}=0.0 \\
\Delta Y^{\circ}=0.5 \\
1-\mathrm{B} \\
4 \text { experiments }\end{array}$}} & \multirow{2}{*}{\multicolumn{2}{|c|}{$\begin{array}{c}\Delta X^{\circ}=0.4 \\
\Delta Y^{\circ}=0.0 \\
2-\mathrm{A} \\
6 \text { experiments }\end{array}$}} & \multirow{2}{*}{\multicolumn{2}{|c|}{$\begin{array}{c}\Delta X^{\circ}=0.0 \\
\Delta Y^{\circ}=1.0 \\
2-\mathrm{B} \\
3 \text { experiments }\end{array}$}} \\
\hline \multirow[t]{2}{*}{ System } & & & & & & & & \\
\hline & $\begin{array}{l}\text { This } \\
\text { paper }\end{array}$ & $\begin{array}{l}\text { Ref. } \\
\text { (1) }\end{array}$ & $\begin{array}{l}\text { This } \\
\text { paper }\end{array}$ & $\begin{array}{l}\text { Ref. } \\
\text { (1) }\end{array}$ & $\begin{array}{l}\text { This } \\
\text { paper }\end{array}$ & $\begin{array}{l}\text { Ref. } \\
\text { (1) }\end{array}$ & $\begin{array}{l}\text { This } \\
\text { papeI }\end{array}$ & $\begin{array}{l}\text { Ref. } \\
\text { (1) }\end{array}$ \\
\hline$D_{11} \times 10^{5}$ & $\begin{array}{r}0.557 \\
\pm 0.003\end{array}$ & $\begin{array}{r}0.559 \\
\pm 0.004\end{array}$ & $\begin{array}{r}1.148 \\
\pm 0.246\end{array}$ & & $\begin{array}{r}1.006 \\
\pm 0.016\end{array}$ & $\begin{array}{r}0.448 \\
+0.006\end{array}$ & $\begin{array}{r}0.439 \\
\pm 0.625\end{array}$. & $\ldots \ldots \ldots$ \\
\hline$D_{12} \times 10^{5}$ & $\begin{array}{r}0.025 \\
\pm 0.039\end{array}$ & -....... & $\begin{array}{r}0.01 \\
\pm 0.002\end{array}$ & $\begin{array}{r}0.016 \\
\pm 0.010\end{array}$ & $\begin{array}{r}0.512 \\
\pm 0.066\end{array}$ & & $\begin{array}{r}0.013 \\
\pm 0.003\end{array}$ & $\begin{array}{r}0.013 \\
\pm 0.008\end{array}$ \\
\hline$D_{21} \times 10^{5}$ & $\begin{array}{r}0.232 \\
\pm 0.017\end{array}$ & $\begin{array}{r}0.232 \\
\pm 0.001\end{array}$ & $\begin{array}{r}0.138 \\
\pm 1.91\end{array}$ & ......... & $\begin{array}{r}0.494 \\
\pm 0.072\end{array}$ & $\begin{array}{r}0.456 \\
\pm 0.003\end{array}$ & $\begin{array}{l}-0.040 \\
\pm 9.969\end{array}$ & ........... \\
\hline$D_{22} \times 10^{5}$ & $\begin{array}{r}1.556 \\
\pm 0.230\end{array}$ & n...... & $\begin{array}{r}1.38 \\
\pm 0.013\end{array}$ & $\begin{array}{r}1.390 \\
\pm 0.002\end{array}$ & $\begin{array}{r}1.122 \\
\pm 0.291\end{array}$ & & $\begin{array}{r}1.469 \\
\pm 0.048\end{array}$ & $\begin{array}{r}1.469 \\
\pm 0.003\end{array}$ \\
\hline$\frac{\sigma_{\mathrm{ext}}^{2}}{\sigma_{\text {int }}^{2}}$ & 5.20 & & 4.32 & ......... & 167.18 & & 38.98 & \\
\hline
\end{tabular}

$E_{X^{\circ}, Y^{\circ}}= \pm 0.02 \% ; E_{X, Y}= \pm 0.02 \% ; E_{T}= \pm 60 \mathrm{~s} ; E_{\beta}=0.1 \%$. 


\section{References}

[1] Kelly, F. J., Ph. D. Thesis, University of New England, Armidale, N.S.W., Australia (1961).

[2] Kelly, F. J., and Stokes, R. H., Electrolytes, pp. 96-100, B. Pesce, Ed. (Pergamon Press Ltd., Oxford, 1962).

[3] Burchard, J. K., and Toor, H. L., J. Phys. Chem. 66, 2015 (1962).

[4] Cussler, E. L., Jr., and Dunlop, P. J., J. Phys. Chem. 70, 1880 (1966).

[5] Onsager, L., Ann. N.Y. Acad. Sci., 46, 241 (1945).

[6] Kirkwood, J. G., Baldwin, R. L., Dunlop, R. J., Gosting, L. J., and Kegeles, G., J. Chem. Phys. 33, 1505 (1960).

[7] Gilliland, E. R., Baddour, R. F., and Goldstein, D. J., Can. J. Chem. Eng. 35, 10 (1957).

[8] Deming, W. E., Statistical Adjustment of Data, pp. 49-58 and pp. 128-147 (John Wiley \& Sons, Inc., New York, New York, 1943 ) (Reprinted by Dover Publications, New York, New York, 1964.)

[9] Guest, P. G., Numerical Methods of Curve Fitting, pp. 370-381 (Cambridge, University Press, Cambridge, England, 1961).

[10] Birge, R. T., Phys. Review 40, 207 (1932).

[11] Box, G. E. P., Bull. Inst. Internat. Statistique 36, 215 (1958).

[12] Hartley, H. O., Technometrics 3, 269 (1961).

[13] Strand, T. G., Kohl, D. A., and Bonham, R. A., J. Chem. Phys. 39, 1307 (1963).

[14] Robinson, R. L., Jr., Edmister, W. C., and Dullien, F. A. L., J. Phys. Chem. 69, 258 (1965).

[15] V an Geet, A. L., and Adamson, A. W., J. Phys. Chem. 68, 238 (1964).

(Paper 73A1-533) 